\title{
Social Representation and Resource Exchange: Comments on Guerin (1995)
}

\author{
YOSHIHISA KASHIMA \\ La Trobe University
}

\begin{abstract}
Bernard Guerin has conducted an insightful and constructive criticism of the current state of social representations research, and pointed to future directions, emphasizing the importance of resource exchange and power process. While agreeing with his general point, this paper attempts to situate Guerin's discussion within the metatheoretical structure concerning the questions about superstructure versus base, intended versus unintended consequences of social action, and metaphysics of social representation. The paper emphasizes the importance of examining the interplay between social representation and resource exchange, and joins Guerin in a call to explore creative methods for studying its dynamics.
\end{abstract}

This paper is one in the series of Bernard Guerin's (1992, 1994) constructive criticism of social representation research from a behavior analytic viewpoint. The author briefly reviews Moscovici's classical study of social representation, presents an intelligent and well informed assessment of the research, and provides some insightful remarks about possible future directions.

I strongly endorse the author's main point that social representation research needs to examine the group dynamics that underpins a social representation. I also agree with the author that this is often a neglected aspect of social representation, or similar other concepts such as culture. However, the author seems to have overemphasized one side of the arguments without presenting the overall structure of a metatheoretical framework. I would like to point out this structure, and facilitate further discussions about relevant issues that are implicit in the author's writing.

\section{1}

One facet of the metatheoretical matrix concerns the issue of superstructure versus base, to borrow the nomenclature of Marxist discourse. This issue addresses relative importance of resource exchange (or contingency of reinforcement) as opposed to ideas and thoughts held by a group of people (or social representation). (Though I am aware of the injustice that this terminology of "ideas and thoughts" dose to the author's sensible discussion of "talking and behaving with respect to ... knowledge (p. 5)", I decided to opt for ease of communication.) The author has, in my opinion, correctly pointed out recent researchers' lack of concern with group

Correspondence concerning this article should be addressed to Yoshihisa Kashima, School of Psychology, La Trobe University, Bundoora, Victoria 3083, Australia. 


\section{Yoshihisa Kashima}

dynamics that underlies any given social representation. The author is well justified in suggesting the objectified nature of social representations as a source of this problem.

However, in pursuing this argument, the author has overemphasized the importance of the base, or the system of reinforcement. In his discussion about the social construction of a social representation that lacks external referents (e. g., Santa Claus, fairies), he suggests that such "fictitious knowledge" is maintained only in a group whose resource exchange does not tightly depend on what is done and said, because "[a]ny arbitrary, counter-intuitive or fictitious behavior or talking would be laughed at or punished (p. 5)".

The main point of this argument is well taken. People are likely to develop a social representation that avoids social punishment. Yet, it is not clear to me why fictitious "knowledges" whose referents science fails to find in the world are to be laughed at or socially punished if a great majority of people hold these "knowledges" to be true. The author appears to assume that fictitious knowledges can be easily detected as fictitious. Nonetheless, given that ghosts and fairies appear to have survived a great many years of human history, I see little force in his argument. Furthermore, there are many tightly knit societies in which animism and shamanism are still well and alive. I would expect that these societies have a system of reinforcement that is as tightly dependent on doing and saying as one can get. Yet, "fictitious knowleges" like spirits seem to survive even then. To say that these societies do not have a tight enough reinforcement system begs a question, how tight is tight enough.

A similar slip appears in his discussion of precontractual contract and power (pp. 8-9). To be sure, a precontractual shared practice of honoring contracts must exist before contracts can be relied upon. Nonetheless, to conclude from it "[a] contract will not maintain unless the parties involved have already settled the power re- lations between them (p. 8)" involves a leap in reasoning. If the author means by power the reward and punishment power of French and Raven (1959), I do not agree with the author's reasoning. Suppose that A has reward and punishment power over $B$, but there is a third party $\mathrm{C}$ to which they can appeal about a contract between $\mathrm{A}$ and $\mathrm{B}$. A and B sign a contract, and A breaks off because even if $B$ tries to force A to carry out the contract, A can punish such an attempt. At this point, B can appeal to $\mathrm{C}$ and somehow demand $\mathrm{C}$ to force $\mathrm{A}$ to honor the contract. If $\mathrm{C}$ has legitimate power to do so, $\mathrm{C}$ will succeed. So, reward and punishment power does not have to be settled before a contract can be honored. In fact, this question touches on the state monopoly of "means of violence" or the power of enforcing the law.

Even if the author includes legitimate power here, and therefore, he covers the above case, I still argue that there is a leap in reasoning. A shared assumption that agreements are to be honored may be enough to ensure the maintenance of a contract. Does this shared assumption involve some settlement of power? It may. But, the author has not shown that it does. I do not see any argument in the author's paper that refutes the position that a sheer shared assumption (or social representation) may be enough to "stop one party simply breaking off" the contract.

What underlies here is the author's underestimation of the "power" of social representation. The author says,

" $[\mathrm{I}] \mathrm{f}$ people in a group tend to agree with each other about a social representation then there must be power relations or group dynamics which came before the representation did. With no pressure beforehand to agree with a community's social representation people would not necessarily agree with it nor continue to agree with it. This is abundantly clear with socially constructed fictitious knowledge, for example (the em- 
phasis in the original, p. 9)”.

Why? Does the author mean to say there needs some pressure logically or causally prior to an agreement with a community's social representation? This sounds awfully like a social contract theory of government in the British tradition championed by Hobbes. People had war of all against all. Then they decided they can't keep on fighting. They finally agreed to have a government. Now, replace "government" with "social representation", and this seems to be the author's position. To my knowledge, this has never been substantiated historically or conceptually.

I believe power is an important issue, and it needs a much finer treatment than it currently receives in social representation research, or social psychology in general for that matter. But, the author may be grossing over too many issues in his crusade. Perhaps he is pointing in the direction of what he calls "social negotiation (p. 8)", as a process of "settlement of power relation". I do agree that social interaction processes between actors in specific situations must be looked at in order to examine the formation and maintenance of social representations, and I also agree that power of some sort has an important bearing on this process. Nonetheless, I do not agree with the author's emphasis on the social exchange process at the expense of shared social representation. I believe it is the interplay between social representation and resource exchange that needs to be examined. One may be able to conceptually start with shared social representation and go to social exchange as well as starting with social exchange and ending up with social representation as the author seems to argue.

\section{2}

The second facet of the metatheoretical matrix concerns relative emphasis of intended as opposed to unintended consequences of social action. Again, given the author's metatheoreti- cal orientation, this distinction may not be relevant. But, his talk of "negotiation (p. 8)" and "use" of social representation to influence group members (p. 10) gives the appearance of intended action. It is perhaps a limitation of English that these words (e.g., negotiation and use) imply planned and intended action, but it does sound like people are assumed to be actively manipulating various means to settle the resource exchange and power relationship. Does the author mean that? Surely, most actors in a society do not always intend to negotiate a social representation, though they may intend to "sort out a few things so that we all come to agree about what went on in the meeting", for instance. My point is that in the latter case, the actor does not intend to negotiate a social representation about the meeting, but intend to sort out disagreements. The agreed upon social representation is then an unintended consequence of the process. By speaking about negotiation and use, the author looks as if he only means a social representation as an intended consequence.

To put it simply, I don't think it is right to speak about negotiating and using social representations exclusively. No doubt people do so sometimes, but in other occasions, people do things and it so happens that a social representation is produced as a consequence without so intended. In other words, there comes to be a social representation in some cases, rather than people negotiating one.

\section{3}

Perhaps, the author is aware of all these. In Conclusion, he seems to make an attempt to redress the balance of his position. He alludes to the langue-parole or language-speech opposition due to Saussure. By implication, the author seems to accord social representation an object like status. He then invokes the familiar argument that social knowledge cannot exist independently of people and social knowledge usually confronts people who are born into it as if it is an external reality. He gives social repre- 
sentation the status of "as if" reality, not quite real, but "virtually" real.

The virtual reality argument reminds me of Anthony Giddens's (1979) characterization of what he calls "structure", which is designed to address an issue similar to social representation. One could go even further than that. Popper (1978) would say there is World 3, which consists of propositions. I suspect ha would not be too shy to make a case for the view that social representation in not virtual, but real, reality. Whether' one treats something like social representation as reality or virtual reality depends on one's metaphysics. While I agree with the author's basically materialist position, I also acknowledge the possibility for a stronger position that postulates the reality of social representation. At times, Moscovici sounds like endorsing this position, I think.

\section{4}

Whether all these make any difference to what one does in studying social representations is probably of most relevance. In this respect, I welcome the author's discussion about methodology. He makes three significant remarks about it in my judgement. First, some anthropological research tools are likely to be useful because anthropologists have traditionally examined a group of people over a long period of time. The author probably means a form of participant observation method, but I do not know if there is a method as such. It would be more useful if the author can list some methods, rather than alluding to anthropology. Anthropologists often say they do not have a methodological training like psychologists do, some pejoratively and others proudly. As typically attributed to Boas, researchers are told to "get a notebook, keep a pencil sharp, and keep your eyes open." This is hardly a useful advice for social representation researchers.

Second, the author suggests that the current methods for studying social representations tend to attribute more coherence to them than warranted. By coherence, the author probably means something like coherence in meaning. Incidentally, this is a typical criticism levelled against symbolic anthropologists like Geertz. By using researchers' own minds (or talking) as a research tool, they are often criticized to make more meaning out of public events than warranted. To this extent, the same criticism applies to some anthropological methods. Then, what method would enable researchers to capture the constantly changing, and yet somewhat stable loose patterns, which are social representations? Do we have such a method?

Third, the point is well taken that often times different groups of people have knowledge of other groups' social representation as well as their own. This is analogous to the situation that Devine (1989) talks about with regard to stereotypes. To paraphrase her research (actually she didn't compare blacks and whites), both blacks and whites in the US know the white stereotypes of blacks being lazy, for instance. But, blacks do not endorse it while some whites do. Methodologically, this requires a fine distinction between an ideation and an attitude towards it. That is, many groups of people may have access to a set of ideational content (e. g., blacks are lazy), however, different groups could have different attitudes toward that content (e.g., agree, disagree, partially agree). A method is necessary that allows researchers to tap both aspects of social representations.

\section{5}

Guerin (1995) makes a significant contribution to the research community of social representation and related concepts. As I suggested in the beginning, I do agree with the general direction of the author's argument. What I wished to do in this short paper was to situate his argument within the metatheoretical matrix involving the three major facets: (1) superstructure versus base, (2) intended versus unintended consequence of social action, and (3) metaphysics of social representation. I also 


\section{Comments on Guerin}

joined Guerin (1995) in a call for the exploration of innovative methods to examine the interplay between social representation and resource exchange.

In the final analysis, Guerin (1995) is grappling with the age old question of individual and society, agency and structure, micro and macro levels of analysis. I applaud his steady efforts and dogged determination in contributing to this research endeavor. I hope this paper makes some contribution, albeit small, in clarifying some of the major issues in this worthy cause.

\section{References}

Devine, G. P. (1989). Stereotypes and prejudice: Their automatic and controlled components. Journal of Personality and Social Psychology, 56, 5-18.

French, J. R. P. Jr., \& Raven, B. H. (1959). The bases of social power. In D. Cartwright
(Ed.), Studies of social power (pp.150167). Ann Arbor: University of Michigan Press.

Giddens, A. (1979). Central problems in social theory. London, UK: Macmillan.

Guerin, B. (1992). Behavior analysis and the social construction of knowledge. American Psychologist, 47, 1423-1432.

Guerin, B. (1994). Analyzing social behavior: Behavior analysis and the social sciences. Reno, NV: Context Press.

Guerin, B. (1995). Some recent and future developments in the study of social representations. Japanese Journal of Experimental Social Psychology, 34, 1-8.

Popper, K. (1978). Hateshinaki Tankyu [Unended quest: An intellectual autobiography] (Hiroshi Mori, Trans.). Tokyo: Iwanami. (original work published 1974).

(Received and Accepted Jan. 20, 1995) 